\title{
VIEWPOINT
}

\section{Responding to Patients Who Refuse to Wear Masks During the Covid-19 Pandemic}

\author{
Eliyahu Y. Lehmann, BA ${ }^{7}$ and Lisa Soleymani Lehmann, MD, PhD, MSc ${ }^{2,3}$
}

'Harvard Global Health Institute, Cambridge, MA, USA; ${ }^{2}$ VA New England Healthcare System, Bedford, MA, USA; ${ }^{3}$ Harvard Medical School and Harvard T.H. Chan School of Public Health, Boston, MA, USA.

J Gen Intern Med 36(9):2814-5

DOI: $10.1007 / \mathrm{s} 11606-020-06323-\mathrm{x}$

(c) Society of General Internal Medicine 2020

A $\mathrm{s}$ states around the country begin lifting restrictions put in place to slow the spread of Covid-19, public health officials are calling for universal masking in crowded spaces, such as grocery stores, pharmacies, and hospitals. SARSCoV-2 spreads person-to-person through close contact and despite current guidelines from the Centers for Disease Control recommending face masks, only a third of Americans wear a mask outside. ${ }^{1}$ With concerningly low rates of the public embracing the recommendation to wear a face mask, patients around the country are showing up at healthcare facilities without masks and some are refusing to wear one. This leaves healthcare professionals with the difficult decision of whether or not to treat patients who do not adhere to masking guidelines. We provide an ethical analysis of the duty to treat patients who refuse to wear a mask and argue that there are justifiable limits on this obligation. We also provide guidance for how clinicians can respond to patients who refuse to wear a mask, encouraging patient engagement and offering the alternative of care through telehealth.

There are many reasons people choose not to wear a mask. Some believe that masks are only needed if you have Covid19 , and a lack of symptoms precludes one from needing to wear one. Early messaging from health experts likely contributed to this misconception as health officials, including the U.S. Surgeon General, communicated that masks were not necessary for the general public's protection. ${ }^{2}$ Guidance has since changed, as it is estimated that over $40 \%$ of people who have the virus are pre-symptomatic or asymptomatic spreaders and are likely unaware of their infectious potential. ${ }^{3,4}$

Others refuse to wear a mask for political reasons, seeing it as a symbolic statement. Republicans are less likely to wear masks than Democrats, with less than $50 \%$ of Republicans wearing masks compared with over $75 \%$ of Democrats. For some, mask-wearing can be viewed as a sign of weakness and

Received July 27, 2020

Accepted October 15, 2020

Published online October 27, 2020 shame, particularly for men. Sixty-seven percent of women reported that they wore masks outside compared to just 56\% of men. ${ }^{1}$ Others may actually choose to not wear a mask as a form of self-preservation. Some Black people have expressed fear of being arrested and targeted by police for wearing masks, leaving them with the difficult choice of deciding which danger is greater - an increased risk of infected or being a target for police. ${ }^{5,6}$

Despite people's reasons for not wearing a mask, doing so significantly reduces the risk of infection and transmission of SARS-CoV-2. A recent review found that the chance of infection when wearing a mask was $3 \%$ compared to $17 \%$ without a mask, a reduction of $85 \%{ }^{7}$ Patients who refuse to wear a mask pose a significant threat to health care professionals and other patients in hospitals and clinics. ${ }^{8,} 9$ Many of these individuals are immunocompromised and have comorbidities that increase the risk of serious complications from the virus.

A recent study found that states that mandated use of masks in public had a significantly greater decline in Covid-19 growth rates after issuing the mandates compared to states that did not issue any mandates. ${ }^{10}$ Given the vulnerability of patients and employees in healthcare environments, it is prudent to require universal masking in all healthcare settings. Requiring patients to wear a mask could be viewed as an infringement on personal liberty. There are, however, limits to personal liberty. The nineteenth-century British philosopher, John Stuart Mill, argued that individuals are free to act as they wish as long as their behavior does not come at the expense of harm to others. ${ }^{11}$ Patients not wearing masks in healthcare facilities clearly violate Mill's Harm Principle, as they pose a significant risk to healthcare workers and patients, thus warranting a restriction of their personal liberty. ${ }^{7,} 12$

Some may argue that healthcare professionals have a moral obligation to treat all patients and that the provision of care should not depend on what a patient wears. However, the duty to care has limits. When patients' behavior poses a risk to healthcare workers and other patients, clinicians are justified in restricting the provision of care. When a patient is disruptive, abusive, or persistently non-adherent, healthcare professionals are ethically justified in terminating the patientphysician relationship. ${ }^{13,}{ }^{14}$ Similarly, as long as a patient is not in need of acute care, healthcare professionals are ethically justified in refusing to provide in-person care to patients who refuse to wear a face covering. 
So how should healthcare professionals respond when patients refuse to wear a face mask? First, we recommend engaging patients to understand their perspective and why they are reluctant to wear a mask. Second, there is an opportunity to educate patients and reinforce the reasons for wearing a mask. These reasons include safeguarding their own health, the safety of healthcare workers, and the safety of other patients. Invoking a civic obligation and the common good as part of the responsibility we all share in preventing the spread of SARS-CoV-2 may resonate with patients. In many cases, this simple conversation may diffuse the situation, leading to adherence with masking guidelines.

Some patients may express a medical reason for refusing to wear a mask. Patients with a mental health illness, those with claustrophobia, or autism may find wearing a mask distressing. Inpatients with altered mental status may also find it challenging to wear a mask. Healthcare professionals can seek to accommodate patients who need in-person care and have a legitimate medical reason for not wearing a mask by offering a face shield. This mechanism of reducing viral transmission may offer protection while providing a more acceptable alternative to patients.

Some patients may not have a legitimate medical reason for refusing to wear a mask and concern for their own well-being or the safety of others may not be sufficient to persuade them to wear a mask. Under such circumstances, patients who do not have an acute medical need should be offered virtual medical care or the option of rescheduling their appointment. Healthcare professionals have quickly transitioned to telehealth and it is clear that many clinical concerns can be addressed through this mode of healthcare delivery.

State policy on universal masking continues to evolve and some have policies requiring mask-wearing in healthcare facilities. ${ }^{15}$ Texas issued a state-wide requirement that masks must be worn by patients and physicians. Massachusetts requires mask-wearing in public places where social distancing is not possible. Ambiguity around what situations require social distancing could result in patients arriving at healthcare facilities without a mask. States and healthcare facilities should provide clear policies on masking requirements in healthcare settings.

It is likely that healthcare professionals and facilities throughout the country will face the challenge of how to respond to patients who refuse to wear a mask. While it is the responsibility of healthcare professionals to treat their patients, exploring patients' reasons for refusing to wear a mask, educating patients on the role that masks play in controlling the spread of SARS-CoV-2, and offering the alternative of virtual care are ways to safeguard the health of patients and healthcare workers. States should develop policies for universal masking in all health facilities. Healthcare professionals can use their platform to educate patients and the public about the importance of mask-wearing, especially in a healthcare setting, and emphasize that masks can be an expression of civic obligation and a badge of pride, worn to protect oneself and those around you.
Corresponding Author: Lisa Soleymani Lehmann, MD, PhD, MSc; VA New England Healthcare System, Bedford, MA, USA (e-mail: LZSLehmann@gmail.com).

\section{Compliance with Ethical Standards:}

Conflict of Interest: The authors have no financial relationships with any organizations that might have an interest in the submitted work and no other relationships or activities that could appear to have influenced the submitted work.

\section{REFERENCES}

1. Ritter Z, Brenan M. New April Guidelines Boost Perceived Efficacy of Face Masks. Gallup. https://news.gallup.com/poll/310400/new-aprilguidelines-boost-perceived-efficacy-face-masks.aspx. Published May 13, 2020. Accessed June 9, 2020.

2. Adams J (@Surgeon_General). Seriously people- STOP BUYING MASKS! They are NOT effective in preventing general public from catching \#Coronavirus, but if healthcare providers can't get them to care for sick patients, it puts them and our communities at risk! Tweet. https:// twitter.com/surgeon_general/status/1233725785283932160?lang=en. Published February 29, 2020. Accessed August 30, 2020.

3. Adams J (@Surgeon_General). In light of new evidence, @CDCgov recommends wearing cloth face coverings in public settings where other social distancing measures are difficult to maintain (grocery stores, pharmacies, etc) especially in areas of significant community-based transmissio. Tweet. April 2020. https://twitter.com/surgeon_general/ status/1246204930022674436?lang=en. Accessed August 30, 2020.

4. Gudbjartsson DF, Helgason A, Jonsson H, et al. Spread of SARS-CoV-2 in the Icelandic Population. N Engl J Med 2020. https://doi.org/10. 1056/nejmoa2006100

5. McFarling UL. Many Black men fear wearing a mask more than the coronavirus. STAT. https://www.statnews.com/2020/06/03/whichdeamany-black-men-fear-wearing-mask-more-than-coronavirus/. Published June 3, 2020. Accessed June 9, 2020.

6. Taylor DB. For Black Men, Fear That Masks to Protect from Covid-19 Will Invite Racial Profiling - The New York Times. The New York Times. https://www.nytimes.com/2020/04/14/us/coronavirus-masks-racism-african-americans.html. Published May 26, 2020. Accessed June 9, 2020.

7. Chu DK, Akl EA, Duda S, et al. Physical distancing, face masks, and eye protection to prevent person-to-person transmission of SARS-CoV-2 and COVID-19: a systematic review and meta-analysis. Lancet. 2020;0(0). https://doi.org/10.1016/S0140-6736(20)31142-9

8. Wang $\mathbf{X}$, Ferro EG, Zhou G, Hashimoto D, Bhatt DL. Association Between Universal Masking in a Health Care System and SARS-CoV-2 Positivity Among Health Care Workers. JAMA. 2020;324(7):703. https:// doi.org/10.1001/jama.2020.12897

9. Klompas M, Morris CA, Sinclair J, Pearson M, Shenoy ES. Universal masking in hospitals in the COVID-19 era. N Engl J Med 2020;382(21):e63. https://doi.org/10.1056/NEJMp2006372

10. Lyu W, Wehby GL. Community Use Of Face Masks And COVID-19: Evidence From A Natural Experiment Of State Mandates In The US. Health Aff 2020;39(8): 1-7. https://doi.org/10.1377/hlthaff.2020.00818

11. Mill JS. On Liberty.; 1859. https://socialsciences.mcmaster.ca/econ/ ugcm/3113/mill/liberty.pdf. Accessed July 21, 2020.

12. Feng S, Shen C, Xia N, Song W, Fan M, Cowling BJ. Rational use of face masks in the COVID-19 pandemic. Lancet Respir Med 2020;8(5):434436. https://doi.org/10.1016/S2213-2600(20)30134-X

13. Senderovitch H. The Ethical and Legal Dilemma in Terminating the Physician-Patient Relationship. Health Law Can 2016;36(4):168-173. https://pubmed.ncbi.nlm.nih.gov/27476245/. Accessed August 30, 2020.

14. Capozzi JD, Rhodes R, Gantsoudes G. Ethics in Practice: Terminating the Physician-Patient Relationship. J Bone Joint Surg Am 2008;90(1):208-210. https://doi.org/10.2106/JBJS.G.01176

15. What U.S. States Require Masks In Public? Masks4All. https:// masks4all.co/what-states-require-masks/. Accessed August 30, 2020.

Publisher's Note: Springer Nature remains neutral with regard to jurisdictional claims in published maps and institutional affiliations. 